Original Article

\title{
Modeling Physical-Chemical Properties of High Dilutions: an electrical conductivity study
}

\author{
Carla Holandino, Rafael Harduim ${ }^{1}$, Venício Feo da Veiga ${ }^{2}$, Sheila Garcia ${ }^{3}$, \\ Carlos Renato Zacharias ${ }^{4}$
}

(1) UFRJ - Rio de Janeiro Federal University, Laboratory of Pharmaceutical Sciences RJ, Brazil (2) UFRJ - Rio de Janeiro Federal University - Microbiology Institute, RJ, Brazil (3) UFRJ - Rio de Janeiro Federal University - Control Quality Laboratory, RJ, Brazil (4) UNESP - São Paulo State University - Chemistry and Physics Department, SP, Brasil

\begin{abstract}
The most common way to perform succussions is to keep place a liquid preparation inside a glass vessel of glass, and shaking beat it violentlyvigorously against a hard elastic surface, either manually or using a mechanical apparatus., or beating it against a hard, but elastic surface in handmade work. This procedure has been interpreted asassumed a mechanism able to transfer the mechanical energy input to the molecular level, where it becomes available to perform chemical work. Such interpretation has been stimulated enforced by observed changes in the electrical conductivity (EC) of High Dilutions (HD) due to the succussion procedure. In order to address this pointquestion, we compared the electrical conductivity changes of HD prepared from Vincristine sulfate (VCR) samples with those relative to theof an inert solvent. The sSamples were produced through manual and mechanical and handmade succusions, in order to observe the influence of bubbles production. The results confirmed the time timing of EC changes but these were equivalent for VCR and solvent, except for VCR $1 \mathrm{cH}$ samples. Also, the production of bubbles does not affect the EC in an extent able to distinguish succussion procedures. We concluded that the physical-chemical properties of HD can be can be modeled by chemical and diffusive mechanisms typical for of distilled water.
\end{abstract}

Keywords: succussion, electrical conductivity, high dilutions, distilled water, modeling

\section{Introduction}

High Dilutions (HD) have been prepared all over the world through a biphasic serial process (named as dynamization) consisted consisting of by dilution and succussion shaking (shakingsuccussion). As the homeopathic therapy is the most successful application of HD, its Pharmacopeia was has been adopted by the HD scientific and technological community. The dilution generally is usually performed as on a decimal or centesimal scale (in per unit of volume) while succussion can be made by manual, mechanical, orhandmade, vortex procedures, among others procedures [1-2].

The proposition of each onepreference for the various successionsuccussion methods is is based on cultural, technological, commercial or philosophical in reasoning. However, experimental models and clinical trials have been demonstrated the efficacy of all these procedures, validating the different succussion techniques [3-7].

The most common way to performmethod of succussions is to place a liquid preparation inside a glass vessel and beat it vigorously against a hard elastic surface, either manually or using a mechanical apparatuskeep a liquid preparation inside a vessel of glass, shaking it violently using a mechanical apparatus, or beating it against a hard, but elastic surface. Succussions were initially proposed by Hahnemann [8], probably inspired on alchemist techniques [9]. Mechanical succussion had its origin probably originated during the on Industrial Revolution, with the desire to produce higher potencies faster, cheaper and more 
standardized [10]. An important feature of mechanical succussion is the intense production of bubbles on in the liquid phase [11-12], when], as compared with those produced by handmade manual succusions. Physical chemistry reasoning leads us to conclude assume that bubbles increase the contact superficial areathe surface area of and increase gasification, and thus, somein some way augment the chemical degradation process. However, no one knowsit is not known if and how this affects the physical structure and biological action of high dilutions [123-134]. Also, succussion procedure has been interpreted as a mechanism that allows transfer of the mechanical energy input all the way down to the molecular level, where it becomes available to perform chemical work [145167].

Some papers have been published suggesting the existence ofliterature suggests unexpected physical chemistry properties and biological implications of high dilutions [178-256]] as well its biological implications, after dynamization procedure. Among these, one can stand out the eElectrical conductivity measurement as is one technique able to observe the dependence changes onof HD dependence on preparation protocols and aging [189-201, 234, 267].

The electrical conductivity of liquid samples measures its ability in to conducting electricity and is influenced by chemical species which tend to ionize in the solution. Therefore chemical degradation and diffusive mechanism diffusion play an important rule in such the process. Also, aqueous systems have its their own natural ionic species [278] others than outsider contaminants.

In this paper, we studied measured the electrical conductivity (EC) of handmade manually and mechanically sucussedioned samples of highly diluted Vincristine sulfate (VCR), measuring theirs electrical conductivity (EC). The main objective was to verify quantify the $\mathrm{EC}$ dependence on time and potency in order to find a mathematical correlation, following as well the physical-chemical effects of different succussion procedures, aiming to propose some interpretationwith the hope of adding to our physical-chemical understanding of these procedures.

\section{Material and Methods}

The starting solution was prepared with Vincristine sulfate - VCR - $\left(\right.$ Zodiac $\left.^{\circledR}\right)$ on in purified water. VCR is a chemotherapeutic agent metabolized by the human organism body at 37 Celsius degree, despite its low storage temperature $\left(-20^{\circ} \mathrm{C}\right)$ [289]. The samples were prepared and stored at room temperature. VCR was choose chosen due our interest in use it to treating neoplastic cell cultures with multidrug resistance (MDR)resistant to VCR, due the phenotype MDR - multidrug resistance
[2930], following according to an the principles of isotherapyic reasoning.

The starting solution consisted on of $1.0 \mathrm{mg} / \mathrm{ml} \mathrm{VCR}$ diluted in $7.5 \mathrm{ml}$ of distilled water, placed in a $10 \mathrm{ml}$ glasstest-tube. Centesimal hahnemannian Hahnemannian potencies were produced until to $15 \mathrm{cH}$ (potentized VCR). Mechanical succussions (Vm group) were performed with one hundred succussions (Denise 10-50, Autic ${ }^{\circledR}$ ) during over 33 seconds (approximately 3 hertz), while handmade ones (Vh group) were performed with similar frequency. In order to register some eventuathel chemical effect of the VCR presence or systematic experimental errors on measurements, equivalent sets of control samples ( 1 to $15 \mathrm{cH}$ ) were prepared with distilled water only, by mechanical $(\mathrm{Wm})$ and handmade manual (Wh) succussions.

In order to reduce eventual chemical release and contaminations, It was used aambar borosilicate (USP type I) glassestest-tubes were used, composed mainly of silicon dioxide and boric oxide, with low levels of the non-network-forming oxides [301], in order to reduce eventual chemical release and contaminations [312]. Furthermore, all samples were analyzed in a differential way, comparing the active sample with its control prepared with solvent only, but processed at in the same waymanner. All glasses test-tubes and plastic stoppers were washed three times with distilled water (Millipore ${ }^{\circledR}$ ) before the startinginitiating samples preparation. The glassesTest-tubes $(10 \mathrm{ml})$ were filled up to $2 / 3$ volume. After each measurement, the samples were thrown away back to glasses, in order to keep the volume ( I didn't understand this sentence, SRS). Any Samples were cultured/monitored??? for microbiological contamination was observed.

Electrical conductivity (EC) measurements were performed on all samples at $250^{\circ} \mathrm{C}$ with systematic calibration and temperature compensation using a Mettler-Toledo MPC 227 apparatus. Intrinsic experimental errors were $0.5 \%$. The potencies $1 \mathrm{cH}$ and $4 \mathrm{cH}$ were selected to evaluate the extent of effects due to the presence of VCR moleculessome ponderal (???) effect; 7, and 9cH toas examples of pre- keep before the Avogadro's limits (mathematically)dilutions and 12 to $15 \mathrm{cH}$, beyond it as post-Avogadro samples. The $\mathrm{Vh}$ and $\mathrm{Vm}$ groups were formed only by potencies at or $\mathrm{n}$ above $4 \mathrm{cH}$ for $\mathrm{n} \geq 4$, excluding samples VCR $1 \mathrm{cH}$. The data from the samples were collected immediately after sample preparation (time zero) and after 7, 14, 21 and 35 days. The glasses samples were kept on at rest in the intervals and no succussions were performed before measurements. Each sample was measured 4 (four) times to evaluate the averaged value and standard deviation. 
Figures 1 to 4 shows the EC time dependence, for VCR and water (control) samples. All electrical conductivity values are on $\mu \mathrm{S} / \mathrm{cm}$ and time in days. The data are presented as averaged value and standard deviation.

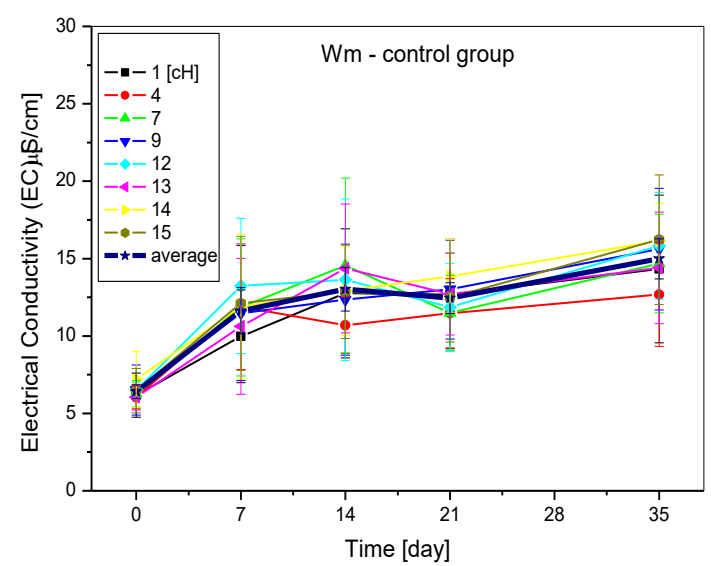

Figure 1: Water control samples - mechanical succussions (Wm). Averaged curves with standard deviation bars are shown for all potencies $(\mathrm{n} \mathrm{cH})$. The bold line is the averaged curve over all potencies.

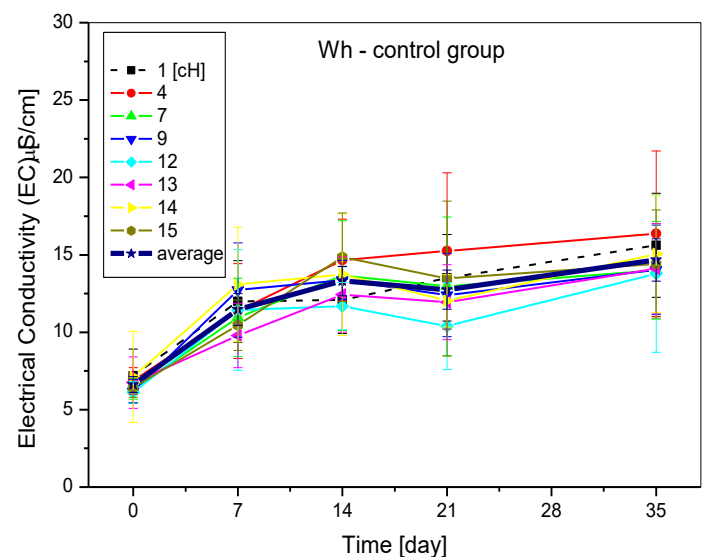

Figure 2: Water control samples - handmade succussions (Wh). Averaged curves with standard deviation bars are shown for all potencies $(\mathrm{n} \mathrm{cH})$. The bold line is the averaged curve over all potencies.

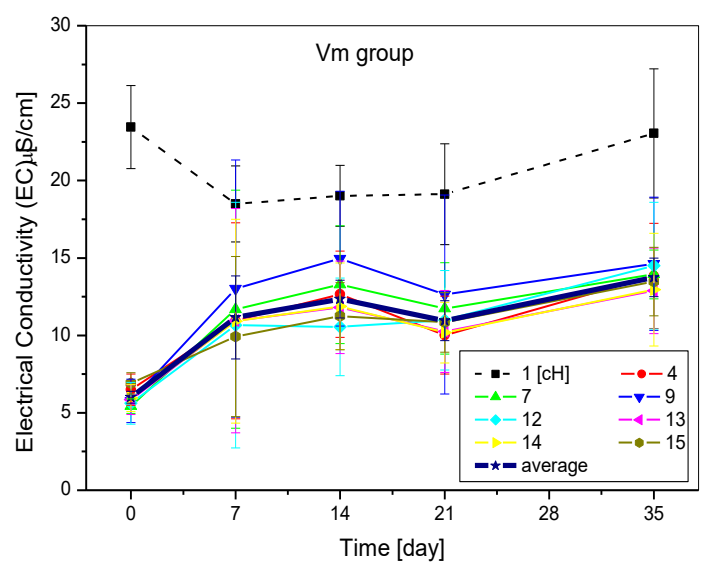

Figure 3: VCR samples - mechanical succussions (Vm). Averaged curves with standard deviation bars are shown for all potencies $(\mathrm{n} \mathrm{cH})$. The bold line is the averaged curve over all potencies, except $1 \mathrm{cH} \quad(n \geq 4)$.

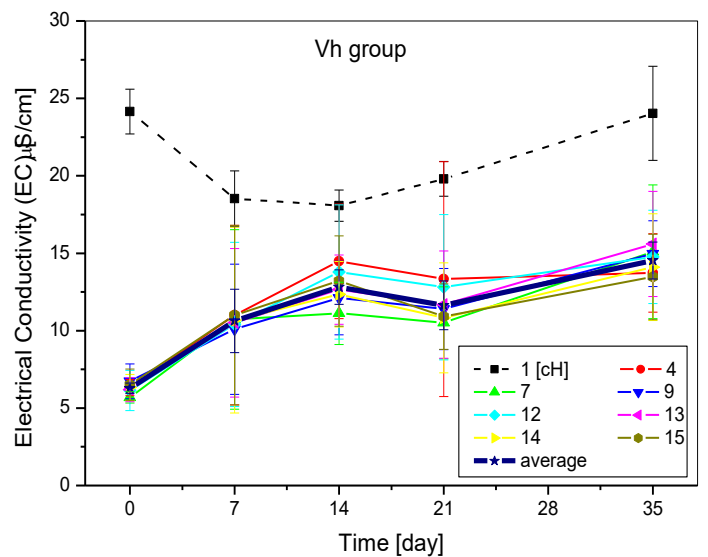

Figure 4: VCR samples - handmade succussions (Vh). Averaged curves with standard deviation bars are shown for all potencies $(\mathrm{n} \mathrm{cH}$ ). The bold line is the averaged curve over all potencies, excep $1 \mathrm{cH}(\mathrm{n} \geq 4)$.

\section{AnalysesAnalysis}

Observing figures 1 to 4 , some common aspects (except for VCR 1cH curves) can be noted: a time dependent increase similar for all potencies and a common starting EC value. Regarding $1 \mathrm{cH}$ samples, the EC time evolution shows two behaviors. The first, up to $7^{\text {th }}$ day, shows a decrease in EC values (from 24 to $18 \mu \mathrm{S} / \mathrm{cm}$ ), followed by a slowly gradual increase. The initial decrease can be probabley be attributed to a chemical degradation. As comment noted earlier, VCR must be stored at $20^{\circ} \mathrm{C}$, despite its clinical use at $37^{\circ} \mathrm{C}$. The samples were prepared and stored, during the measurement period, at room temperature (about $25^{\circ} \mathrm{C}$ ).

A second effect can may be attributed to distilled water dynamics, as will be discussed latter. From $7^{\text {th }}$ to $35^{\text {th }}$ day one can observe a slight increasing on in EC, similar for to those observed to $\mathrm{Vm}$ and 
Vh groups, as well to water control (Wm and Wh). However, these curves will not be interpreted in this article. They were collected only to verify up to what extent the presence of VCR molecules affects the EC. One can realize from figures 3 and 4 that for VCR 4cH and higher, EC results reveal a nonmeasurable presence of VCR molecules and theirs derivatives.

Let's starting the main discussion from the control groups (Wm and Wh), shown iIn figures 1 and 2. All curves show the same time dependence: an initial fast rapid increase of $\mathrm{EC}$ up to day $7^{\text {th }}$, starting from EC value about $6.0 \mu \mathrm{S} / \mathrm{cm}$, followed by an asymptotical convergenceconvergence, similar for all potencies (within standard deviations) and independent from of the performed succussion technique. Thus, one can calculate an averaged curve representative of $\mathrm{Wm}$ and $\mathrm{Wh}$ groups (figure $5)$.
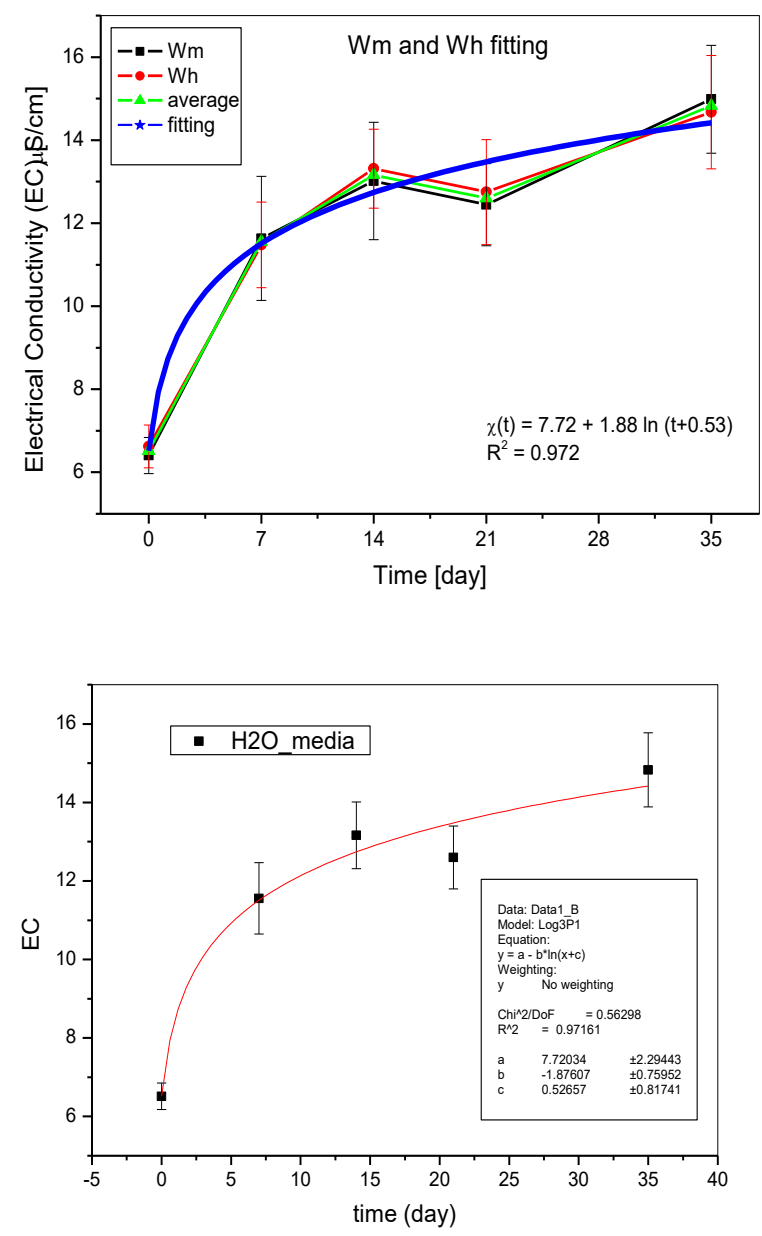

Figure $5-\mathrm{Wm}$ and $\mathrm{Wh}$ data. Experimental points (average and standard deviation) are shown in squares $(\mathrm{Wm})$ and circles(Wh). The averaged curve is shown (triangles as dotted). The bold curve is the logarithm fitting (see details in text and table 1). The fitted function and determination coefficient $\left(r^{2}\right)$ are also shown in the box.
Wm and Wh groups have similar behaviors, despite the different succussion procedures and, as well the potencies. Thus, one can assume that this is the behavior for the control dynamized distilled water. The EC values for distilled water used on preparations, while kept at rest, were $(2.76 \pm 0.16)$ $\mu \mathrm{S} / \mathrm{cm}$, typical of values for distilled water [1]. Accordingly According to figure 5, the initial value for dynamized water $(\mathrm{EC}$ for $\mathrm{t}=0$ ) was about 6.5 $\mu \mathrm{S} / \mathrm{cm}$. This value means that the dynamization procedure, in special theparticularly the succussionssuccuessions, alters the physicalchemical properties of water, probably due to gasification and bubbling.

The time dependence can be attributed to a typical water dynamics [278,3332] as distilled water is a non-equilibrium system. The natural and more stable water state is reached by the equilibrium of molecular species, ionic contaminants, dissolved gases and solutes, aerosols, and silica among others. substances. As the samples were prepared using special glasses test-tubes and distilled water, the molecular dynamics might be driven mainly by the intrinsic water ions formation and dissolved gases and aerosols. Ions formation and other chemical reactions generally are very fast rapid processes, while gasification or diffusive mechanisms are slower. $\mathrm{Wm}$ and $\mathrm{Wh}$ groups exhibited similar behaviors for all measured time and for all potencies, indicating that if gasification really happens, it might be important only during the first hours after succussions, but would not strongly influence strongly the chemical stabilization of the solutions. One can visualize this fast rapid dynamic period in figure 5: up to the first four days after succussionsuccuession $\mathrm{s}$ be performed the EC values change significantly. After 35 days the system reach an EC values about 14.4 $\mu \mathrm{S} / \mathrm{cm}$, an intermediated value between fresh and aged distilled water [334-345].

The EC time dependence of $\mathrm{Wm}$ and $\mathrm{Wh}$ groups (figure 5) suggests a fast rapid dynamic in the first 7 days, followed by a slowly convergence to a stable value (aged water). Such behavior can be fitted approximated by many mathematical functions. One convenient function can be proposed from the natural logarithm, defined as

$$
\chi(t)=A+B \ln \left(t+t_{r}\right)
$$

where the coefficients $\mathrm{A}, \mathrm{B}$ and $\mathrm{t}_{\mathrm{r}}$ can be adjusted numerically. Physically, this function describes an increasing logarithmic behavior weighted by $\mathrm{B}$, time shifted by a factor $t_{r}$ with a baseline given by A.

The fitting of suchthis function to experimental data is shown in figure 5 and the fitted coefficients are reported in table 1 : 
Table 1: logarithm fitting for water groups (averaged curve)

\begin{tabular}{ll}
\hline $\mathbf{X}(\mathbf{t})=\mathbf{A}+\mathbf{B} \ln \left(\mathbf{t}+\mathbf{t}_{\mathbf{r}}\right)$ & Numerical fitting \\
\hline $\mathbf{A}$ & $7.72[\mu \mathrm{S} / \mathrm{cm}]$ \\
$\mathbf{B}$ & $1.88[\mu \mathrm{S} / \mathrm{cm} . d a y]$ \\
$\mathbf{t}_{\mathbf{r}}$ & $0.53[\mathrm{day}]$ \\
$\mathbf{r}^{2}$ & 0.972 \\
\hline
\end{tabular}

For VCR groups, the analyses can be done in two steps: one related to $1 \mathrm{cH}$ samples only and the other, to all others potencies. Figures 3 and 4 refer to VCR groups (Vm and Vh). At a first glance, one can may note that, except for $1 \mathrm{cH}$ samples, the EC time dependence is similar for all potencies and are independent from the succussion procedure. The exception for of $1 \mathrm{cH}$ samples can be understood by the presence of molecules of VCR $(10, .0 \mu \mathrm{g} / \mathrm{ml})$, able to affect the $\mathrm{EC}$ values. For $4 \mathrm{cH}$ samples, the concentration reaches a mathematical value of $1, .0$ $\mathrm{ng} / \mathrm{ml}$, and the EC remains similar for all higher potencies (within experimental deviations). Thus, we assumed that after $4 \mathrm{cH}$ the $\mathrm{EC}$ time dependence is governed only by solvent effects others than the presence of VCR molecules or theirs derivatives. These curves can be analyzed through averaged curves (figure 6) as well fitted by a logarithm function, as reported in table 2 :
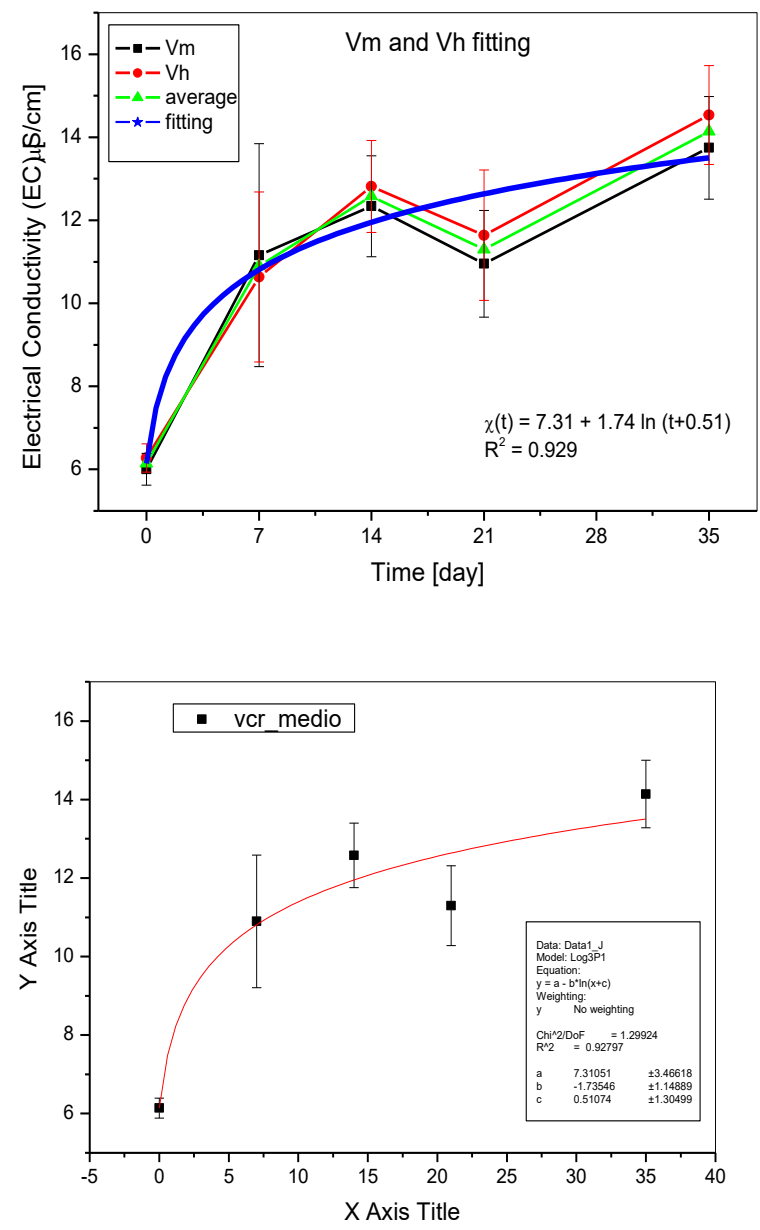

Figure $6-\mathrm{Vm}$ and $\mathrm{Vh}$ ddata. Experimental points (average and standard deviation) are shown in squares $(\mathrm{Vm})$ and circles $(\mathrm{Vh})$. The averaged curve is shown as trianglesdotted. The bold curve is the logarithm fitting (see detais in text and table 2). The fitted function and determination coefficient $\left(\mathrm{r}^{2}\right)$ are also shown in the box.

Table 2: logarithm fitting for VCR groups (averaged curve)

\begin{tabular}{ll}
\hline$X(t)=A+B \ln \left(t+t_{r}\right)$ & Numerical fitting \\
\hline$A$ & $7.31[\mu \mathrm{S} / \mathrm{cm}]$ \\
$B$ & $1.74[\mu \mathrm{S} / \mathrm{cm}$. day $]$ \\
$\mathbf{t}_{\mathbf{r}}$ & $0.51[$ day $]$ \\
$\mathbf{r}^{2}$ & 0.929 \\
\hline
\end{tabular}

Comparing both fitted curves (figure 7) as well theirs fitted parameters (tables 1 and 2) one can note that they show the same general behavior, meaning the chemical process involved might be similar for both groups. However, one can note that VCR groups show a slower convergence (smaller B 
coefficient) with a slight smaller baseline value (A coefficient), with equivalent time shift $\left(t_{r}\right)$.
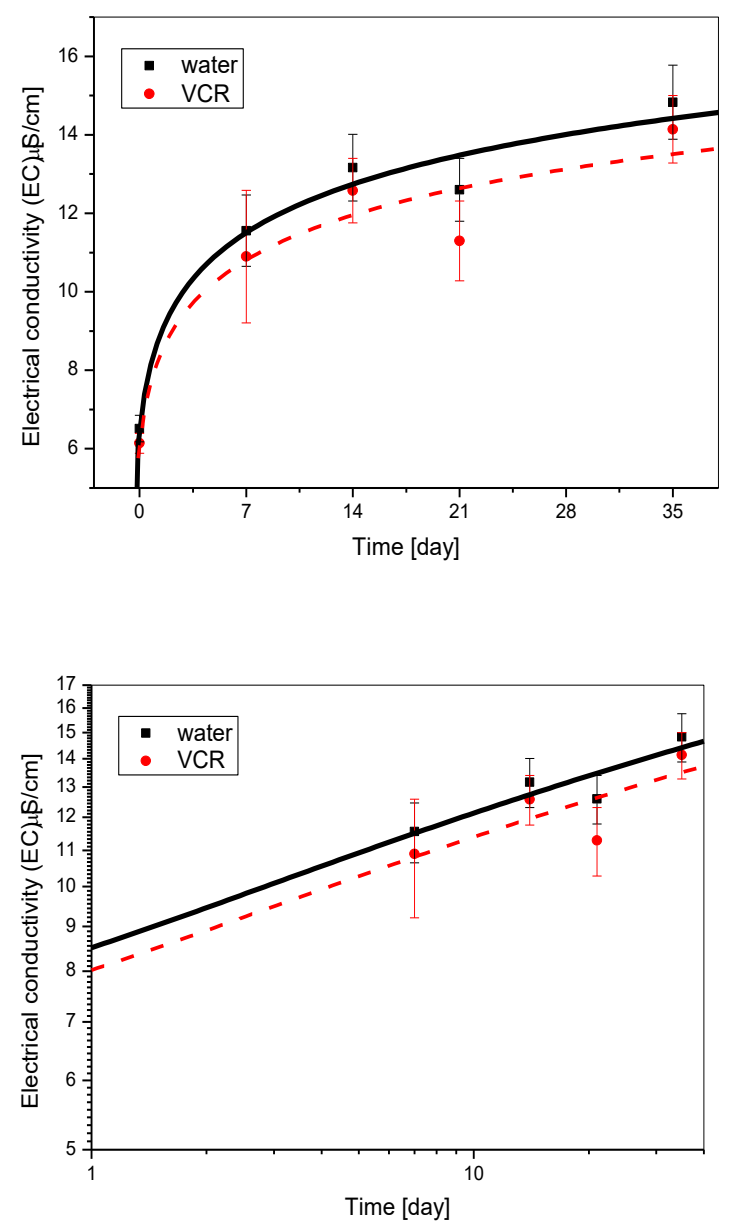

Figure 7- Comparison between fitted curves (water and VCR). The upper graphics is plotted in linear scale and the lower one, in log-scale. Averaged data (average and standard deviation) are shown in squares for water group and in circles for VCR one. The continuous curve is the logarithm fitting for water and the dashed for VCR. In the lower graphics one can realize recognize the systematic difference between curves (see details in text).

The differences between VCR (for $\mathrm{n} \geq 4$ ) and water samples might suggest some effect based on the samples historiesy: while VCR set originates in contact with VCR molecules, the water set had never be put in contact with any substance other than distilled water.

In some aspects it can be seen as a memory effect, though chemically supported. One can suppose that the degradation process of VCR molecules originates creates some products or chemical species able to rearrange the solvent in order to release or neutralize others species involved in the solvent electrical properties as theseen in electrical conductivity. Considering this neutralizing process happensing in the first few hours, it one would be expected smaller values for EC because some (neutralized) species contributes no more for EC changes. One must observe keep in mind that the samples preparation from $1 \mathrm{cH}$ to $15 \mathrm{cH}$ spends requires some time in itself from $1 \mathrm{cH}$ to $15 \mathrm{cH}$. Further, considering the EC changes occurs by different chemical channels, the elimination of some of them can reduces, but not eliminates at all, the EC temporal changes.

\section{Mathematical Modeling}

The EC time dependence showed in figure 7 and fitted by equation 1 by values reported on table 1 and 2 suggests a slow chemical process, probably due to gasification or diffusion.

Let's consider a general chemical reaction (eq. 2) where some reagents $\left(R_{i}, i=1, L\right)$ produce two sets of products $\left(P_{j}, j=1, M\right)$ and $\left(P_{k}, j=1, N\right)$ in such way that only products $\mathrm{P}_{\mathrm{k}}$ are involved in the electrical conductivity time dependence.

$$
\sum_{i=1}^{L} c_{i} R_{i} \rightleftarrows \sum_{j=1}^{M} c_{j} P_{j}+\sum_{k=1}^{N} c_{k} P_{k}
$$

For simplicity, all products $\mathrm{P}_{\mathrm{k}}$ will be treated as one and the effective molar concentration will be named as $[\mathrm{P}]$. As the chemical reaction proceeds, [P] changes in over time. Let's suppose that such time dependence can be described by a power law (eq. 3)

$$
[P](t)=P_{0} \alpha(t)\left(t+t_{0}\right)^{c}
$$

where $[\mathrm{P}](\mathrm{t})$ is the $[\mathrm{P}]$ value at the instant $\mathrm{t}(\mathrm{mol} / \mathrm{l})$, $\mathrm{t}$ is the time (day), $\mathrm{P}_{0}$ is the $[\mathrm{P}]$ for $\mathrm{t}=0$, $\mathrm{a}(\mathrm{t})$ is a function related to the reaction speed $\left(\right.$ day $\left.^{-1}\right)$, $c$ is the exponent that governs the $[\mathrm{P}]$ time dependence (reaction order) and $t_{0}$ is a reference time indicating that the reaction has already started before $t=0$ (day).

The use of a power law for fitting is convenient because by adjusting the exponent $\mathrm{c}$ one can model different time dependences as described in table 3 .

Table 3 - Time dependence accordingly exponent c.

\begin{tabular}{ll}
\hline c value & Interpretation \\
\hline $\mathbf{c}<\mathbf{0}$ & {$[\mathrm{P}]$ decrease in time } \\
$\mathbf{c}=\mathbf{0}$ & {$[\mathrm{P}]$ is constant } \\
$\mathbf{0}<\mathbf{c}<\mathbf{1}$ & $\begin{array}{l}{[\mathrm{P}] \text { increase accordingly a dissipative }} \\
\text { dynamics }\end{array}$ \\
$\mathbf{c}=\mathbf{1}$ & {$[\mathrm{P}]$ increase linearly in time } \\
$\mathbf{c}>\mathbf{1}$ & $\begin{array}{l}{[\mathrm{P}] \text { increase accordingly a cooperative }} \\
\text { dynamics }\end{array}$ \\
\hline
\end{tabular}

The assumption of speed reaction time dependent $[a(t)]$ is important because as $t \rightarrow \infty$ the reaction must stop (dynamical equilibrium) due to the 
consumption of reagents or inversion in the reaction direction. However, as we have measured the EC time dependence only during the first 35 days, and figure 7 indicates that the reaction continues for larger longer times, we will assume that $\alpha(t)$ is a constant, named only as $\alpha$.

So, eq. 3 can be rewrite as

$$
[P](t)=P_{0} \alpha\left(t+t_{0}\right)^{c} \quad(\text { eq. } 4)
$$

The values of $\mathrm{P}_{0}, \mathrm{a}, \mathrm{t}_{0}$ and $\mathrm{c}$ can be determined by fitting with averaged experimental values (figure 7). As the obtained experimental data refers to EC values, one has to establish a correlation between [P] and EC. As far as the authors knows, such correlation seems to be non- trivial. However, it is well known that the measurement of $\mathrm{pH}$ and $\mathrm{EC}$ are technically similar, based on ions transport. The relation between $\mathrm{pH}$ and molar concentration is defined through a logarithm function. Thus, one can propose an equivalent relation to $\mathrm{EC}$ and $[\mathrm{P}]$ as defined in eq. 5 .

$$
\frac{\chi(t)}{\chi_{0}}=\ln \left(\frac{[P](t)}{P_{0}}\right)
$$

where, $\mathrm{X}(\mathrm{t})$ and $[\mathrm{P}](\mathrm{t})$ are, respectively, the EC and molar concentration of $\mathrm{P}$ at any time $\mathrm{t}$ and $\mathrm{X}_{0}$ and $\mathrm{P}_{0}$ are the respective initial values. The hypothesis proposed in eq. 5 involves relative quantities to simplification and dimensional adjustment.

Starting from eq. 4, one can calculate the EC time dependence as bellow:

$$
\begin{gathered}
\frac{[P](t)}{P_{0}}=\alpha\left(t+t_{0}\right)^{c} \\
\ln \left(\frac{[P](t)}{P_{0}}\right)=\ln \left(\alpha\left(t+t_{0}\right)^{c}\right) \\
\ln \left(\frac{[P](t)}{P_{0}}\right)=\ln (\alpha)+c \ln \left(t+t_{0}\right)
\end{gathered}
$$

The left term can be substituted accordingly eq. 5 to obtain

$$
\frac{\chi(t)}{\chi_{0}}=\ln (\alpha)+c \ln \left(t+t_{0}\right)
$$

Finally we can state,

$$
\chi(t)=\chi_{0} \ln (\alpha)+\chi_{0} c \ln \left(t+t_{0}\right)
$$

Equation 6 has the same mathematical structure as the eq. 1, used to fit experimental data. Comparing both equations we can identify parameters $\mathrm{A}, \mathrm{B}$ and $t_{r}$ as:

$$
\begin{aligned}
& A=\chi_{0} \ln (\alpha) \\
& B=\chi_{0} c \\
& t_{r}=t_{0}
\end{aligned}
$$

\section{Numerical Fittings}

In order to compare eqs. 8 to 10 with numerical data reported on in tables 1 and 2, one first needs to determine $\mathrm{X}^{0}$ values for water (W) and VCR (V) averaged curves. These can be calculated from data on tables 1 and 2 , imposing $\mathrm{t}=0$ in eq. 1 . Thus one obtains $\mathrm{X}_{0}=6.5$ and $6.1 \mu \mathrm{S} / \mathrm{cm}$ for water and VCR groups, respectively. Then, the parameters A, B and $t_{r}$ can be calculated, as reported on table 4

Table 4: numerical fitted parameters

\begin{tabular}{llll}
\hline Parameter & Water & VCR & average \\
\hline a $\left(\right.$ day $\left.^{-1}\right)$ & 3.28 & 3.31 & 3.30 \\
c & 0.289 & 0.284 & 0.287 \\
t $_{\mathbf{0}}$ (day) & 0.53 & 0.51 & 0.52 \\
\hline
\end{tabular}

The values reported on table 4 indicate that the chemical temporal dynamics for water and VCR are similar. As discussed before, the differences observed on figure 7 might be explained as a consequence of the initial VCR degradation, while the samples were being prepared or in during the first hours after preparation. The similar values reported on table 4 come to reinforce this hypothesis. So, it is convenient calculate the averaged values for these parameters.

The parameter c reveals a dissipative dynamics where the continuous formation of the product $\mathrm{P}_{\mathrm{k}}$ inhibits the chemical reaction and thus, the increase of the EC. From eq. 4 and table 4 one can determine the relative molar concentration $\left(\mathrm{M}_{\mathrm{p}}\right)$ as well its formation speed $\left(\mathrm{sp}_{\mathrm{p}}\right)$ as given below:

$$
\begin{gathered}
M_{p}(t)=\frac{[P](t)}{P_{0}}=3.30(t+0.52)^{0.287} \\
s_{p}(t)=\frac{d}{d t}\left(\frac{[P](t)}{P_{0}}\right)=0.95(t+0.52)^{-0.71}
\end{gathered}
$$

$M_{p}(t)$ and $S_{p}(t)$ can be visualized on in figure 8 . 


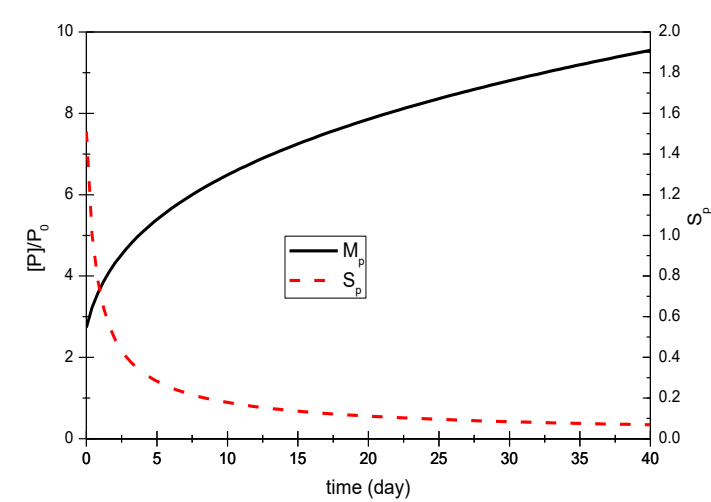

Figure 8 - relative molar concentration $\left(\mathrm{M}_{\mathrm{p}}\right)$ and product formation speed $(\mathrm{sp})$.

Figure 8 shows that the reaction speed reduces to $50 \%$ in 1 day and $25 \%$ after 7 days, when the second set of measurements were collected. Thus, the details of this fast dynamics could not be directly observed. After the $7^{\text {th }}$ day, the speed decreases slowly, as the relative molar concentration increase almost linearly. As discussed before, the reaction must reach a steady condition state represented by stable concentrations and speed values. However, this condition was not observed within the first 35 days.

\section{Conclusions}

The first objective of this work was compare mechanically and handmade manually succussioned succussed highly diluted samples through regarding a physical chemical parameter. The selection for of electrical conductivity was based on recently published articles suggesting the existence of a complex dynamic of the water able to exhibit memory and time dependent effects.

As the starting initial solution contained molecules of VCR and was prepared at room temperature, chemical degradation was expected. Thus, we analyzed VCR data only for potencies $4 \mathrm{cH}$ or higher. The control samples were prepared using the same protocol using only distilled water.

Mechanical succussions are known to produce intense bubbling when compared to handmade ones. Bubbles, further beyond beingthan a mechanical agent, means an increase in the contact air-liquid area generally affecting the speed of reactions. Thus, a chemically instable substance submitted to bubbling would reveal differences when compared to water control samples.

The experimental results really showed differences between VCR and control samples (figure 7) but these were systematic (figure 7, lower graphic).

These differences could be explained by chemical effects in the first days after samples preparation. Such a hypothesis was reinforced by the calculation of the model parameter, reported on table 4, similarly valued for both groups of samples, as well for the .

Further the similarity between for of VCR and control samples, in all potencies $(\mathrm{n} \mathrm{cH})$ showed similar results too.

The mMathematical modeling required requires the assumption of a relationship between EC and [P] (eq. 5). Despite its similarity with the concept of $\mathrm{pH}$ concepts, this assumption must be harder studied further to be confirmed. The use of a power law to fit EC time dependence is not critical, because this function can describe a lotmany of natural phenomena and the parameters were adjusted from experimental data, getting obtaining a correlation factor almost unitary (see tables 1 and 2).

The main conclusion is that water shows a slow dynamics, probably driven mainly by diffusive mechanisms without relation with any special property of the dynamization procedure, rather beyond than mechanical agitation. Memory effect can be understood as a time shift in such dynamics. Bubbling represents an important process only when some an instable substance is present. For samples prepared with distilled water only, no difference was observed between $1 \mathrm{cH}$ and higher potencies. However, all potencies for both groups showed an increase of EC even at the first measurements, when compared with distilled water kept in at rest. It Our findings are is in agreement with the well known feature fact that the distilled water is an out-of-equilibrium state and naturally goes to a maximum entropy state, especially when perturbed by bubbling and mechanical agitation.

All these conclusions are strongly limited to electrical conductivity measurements. No biological implication can be extracted directly from these results, unless some until further biological experiments are doneperformed, in order to correlate EC with biological effects [356].

Despite the findings reported in this article indicate that dynamized Vincristine is not different from water (in terms of EC), it does not means that HDs do not have biological action. One cannot invalidate the biological activity evidences based on isolated EC results or any other physical-chemical parameter. HD biological activity is not well understood and some evidences seem to indicate that a biological sensor is required to observe the responses. If this hypothesis is true, non-biological studies should be secondary to characterize a HD. Much research work is required to clear this point.

\section{Acknowledgements}


This work was supported by Conselho Nacional de Desenvolvimento Científico e Tecnológico (CNPq), Fundação de Amparo a Pesquisa no Estado do Rio de Janeiro (FAPERJ), Fundação José Bonifácio (FUJB), Fundação Ary Franzino/Fundação Educacional Charles Darwin (FAF/FECD/ONCO) and Projetos de Pesquisa para o Sistema Único de Saúde (PPSUS/FAPERJ).

\section{References}

[1] Brazilian Homeopathic Pharmacopeia. $2^{\circ}$ ed, vol. 1. São Paulo: Atheneu Editora, 1997.

[2] The Homeopathic Pharmacopoeia of the United States. 8th ed, vol 1. Virginia (United States): American Institute of Homeopathy; 1979.

[3] Belon P, Cumps J, Ennis M, et al. Histamine dilutions modulate basophil activation. Inflamm Res. 2004; 53(5): 181-188.

[4] Bonamin LV, Lagache A, Bastide M. Research on Ultra-dilutions and the theory of corporeal signifiers: the follow up. In: Bonamin LV, (ed)itor.. Signals and Images: Contributions and Contradictions about High Dilution Research. Heidelberg (Deutschland): Springer;; 2008,. p.3-25.

[5] Quino CL, Barbosa GM, Barbosa GM, Varricchio MCBA, Veiga VF, Kuster R, Zancan P, Sola-Penna M, Quaresma CH. High dilutions of Euphorbia tirucalli L. (AVELOZ) modify the viability and glycolytic metabolism of cell lines. Int J High Dilution Res [online]. 2008 [cited 2008 oct 05]; 7(24): 132-139. Available from: http://www.feg.unesp.br/ ojs/index.php/ijhdr/article /view/283/361.

[6] Shang A, Müntener-H K, Nartey L, et al. Are the clinical effects of homoeopathy placebo effects? Comparative study of placebo-controlled trials of homoeopathy and allopathy. Lancet. 2005; 366: 726-732.

[7] Varricchio MCBN, Aquino CL, Moreno GB, Pereira FG, Veiga VF, Zancan P, Sola-Penna M, Kuster RM, Holandino C. Cytotoxicity and antitumoral activity of extremely diluted solutions of Euphorbia tirucalli Lineu: an in vitro study. Proceedings of the Improving the Success of Homeopathy 5: A global perspective; 2006; London, United Kingdom. London: Royal London Homeopathic Hospital pp 141, 2006, London. p 141.

[8] Hahnemann S. Organon of Medicine. 6th edn. London: , Orion Books Ltd;, §270, 2003. §270.

[9] Ruiz R. Da Alquimia à Homeopatia., Bauru (Brazil), : Edusc,; 2002.

[10] Wiston J. A brief history of potentizing machines.. British Homeopathic J. 1989; 78(1): 5968.

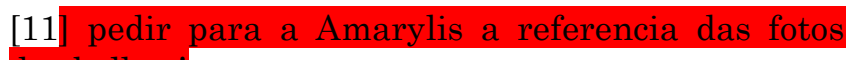

[112] Holandino C, Leal FD, Barcellos BO, Campos MA, Oliveira R, Vega VF, Garcia S, Zacharias CR. Mechanical versus Handmade Succussions: a physical chemistry comparison. In: Bonamin LV, (ed)itor. Signals and Images: Contributions and Contradictions about High Dilution Research. Heidelberg (Deutschland): Springer;, 2008, p.37-48.

[123] Vallée P, Lafait J, Legrand L, Mentré P, Monod MO, Thomas Y. Effects of pulsed lowfrequency electromagnetic fields on water characterized by light scattering techniques: role of bubbles. Langmuir. 2005; 21: 2293-2299.

[134] Rey L. Thermoluminescence of ultra high dilutions of lithium chloride and sodium chloride. Physica A. 2003; 323: 67-74.

[145] Torres, JL. Physical basis of succussion. Homeopathy. 2002; 91(3): 221-224.

[156] Anagnostatos, G.S.,. Small water clusters (clathates) in the preparation process of Homeopathy. In: Endler PC, Schulte J, (Eeds)itors,. Ultra High Dilution: Physiology and Physics. Dordrecht (Nederland): Kluwer Academic Publishers;, 1994,. 121-128.

[167] Auerbach D. Mass, fluid and wave theory motion during the preparation of the ultra high dilutions. In: In. Endler PC, Schulte J, (Eeds)itors,. Ultra High Dilution: Physiology and Physics. Dordrecht (Nederland): Kluwer Academic Publishers;, 1994,. 129.

[178] Elia V, Baiano S, Duro I, Napoli E, Niccoli M, Nonatelli L. Permanent physical chemistry properties of extremely diluted aqueous solutions of homeopathic medicines. Homeopathy. 2004; 93(2): 144-150.

[189] Elia V, Elia L, Cacace P, Napoli E, Niccoli M, Savarese F., The extremely diluted solutions as multi-variable systems: a study of calorimetric and conductometric behaviour as a function of the parameter time. J. Thermal Analysis and Calorimetry. 2006; 84(2): 317-323.

[1920] Elia V, Marchese M, Montanino M, Napoli E, Niccoli M, Nonatelli L, Ramaglia A. Hydrohysteretic phenomena of extremely diluted solutions induced by mechanical treatments: a calorimetric and conductometric study at $25^{\circ} \mathrm{C}$. J . Solution Chemistry. 2005; 34(8): 947-960.

[201] van Wijk R, Bosman S, van Wijk EP. Thermoluminescence in ultra-high dilution research.. J Altern Complement Med. 2006; 12(5): 437-443. 
[212] Lobyshev VI, Shikhlinskaya RE, Ryzhikov BD. Experimental evidence for intrinsic luminescence of water. J. Molecular Liquids. 1999; 82: 73-81.

[223] Samal S, Geckeler KE. Unexpected solute aggregation in water on dilution. Chem. Commun. 2001;; 21: 2224-2225.

[234] Walach H, Assendonk T, Bourkas P, Delininick A, Ives G, Karraginnopoulos C, Lüdtke R, Wassenhoven M, Witt C. Electric measurement of ultra-high dilutions - a blinded controlled experiment. Brit. Homeophatic J. 1988; 87: 3-12.

[254] Klimek W, Yan Y, Tschulakow AV. A new approach to the memory of water. Homeopathy. 2005; 94: 241-247.

[256] Elia V, Napoli E, Germano R. The "Memory of Water": an almost deciphered enigma. Dissipative structures in extremely dilute aqueous solutions. Homeopathy. 2007; 96(3): 163-169.

[267] Miranda AR. Water and High Dilutions Phenomenology: Physical Characterization. In: Bonamin LV, (ed)itor. Signals and Images: Contributions and Contradictions about High Dilution Research., Heidelberg (Deutschland): Springer;, 2008,; p.49-63.

[278] Chaplin MF. The memory of water: an overview. Homeopathy. 2007; 96(3): 143-150.

[289] BIOMOL International [cited 2008 Oct 08]., [about $1 \mathrm{p}$ ]. Available from:

http://www.biomol.com/SiteData/docs/productdata/T 117.pdf , (08 Oct 2008).

[2930] Holandino C, Veiga VF, Rodrigues ML, Morales MM, Capella MAM, Alviano CS. Direct current decreases cell viability but not $P$ Glycoprotein expression and function in human multidrug resistant leukaemic cells. Bioelectromagnetics. 2001; 22: 471-478.

[301] Gennaro ENNARO, A.R., (Eed)itor. Remington: The Science and Practice of Pharmacy. 20. ed. Philadelphia (United States): Lippincott Williams \& Wilkins;, 2000

[312] Milgrom LR, King KR, Lee J, Pinkus AS, On the investigation of homeopathic potencies using low resolution NMR T2 relaxation times: an experimental and critical survey of the work of Roland Conte et al. Br Homeopathic J. 2001; 90: 513.

[323] Teixeira J. Can water possibly have a memory? A sceotical view. Homeopathy. 2008; 96(3): 158-162.

[334] Lennetech Water Conductivity. Water Conductivity Lenntech[online]. Delft (The Netherlands); 2008. [updated 2008 Jan 05; cited 2008 Oct 08]., Available from:

http://www.lenntech.com/water-conductivity.htm, (08 Oct 2008).

[345] Amber Science Inc. Conductivity. Eugene (United States); 2008 [updated 2008 Mar 10; cited 2008 Oct 08]. Available from:

http://www.amberscience.com/reference.html, $\quad(08$ Oct 2008).

[356] Zacharias CR. Theoretical and PhysicalChemical Models for Dynamized Systems: validation creiteria. In: Bonamin, LV, (ed)itor. Signals and Images: Contributions and Contradictions about High Dilution Research. Heidelberg (Deutschland): Springer;, 2008, p. 29-35.

(c)) BY-NC-ND Licensed to GIRI

supported by CNPq, FAPERJ, FUJB, FAF/FECD/ONCO, PPSUS/FAPERJ.

Conflict of interest: authors declare there is no conflict of interest

Received: 01 Nov 2008; 2008; Revised 1510 Dec 2008; Published: 3018 Dec 2008

Erratum: 30 Dec 2008. (http://www.feg.unesp.br/ ojs/zacha_ijhdr/erratum/?v=7\&i=25\&pi=165)

Correspondence author: Carlos Renato Zacharias, zacha@feg.unesp.br

How to cite this article: Holandino C, Harduim R, Veiga VF, Garcia, S. Zacharias CR. Modeling physical-chemical properties of High Dilutions: an electrical conductivity study. Int J High Dilution Res [online]. 2008 [cited YYYY Mmm DD]; 7(25): 165-173xx-yy. Available from: http://www.feg.unesp.br/ ojs/index.php/ijhdr/article/view/319/375. 